\title{
Reducing Defects in Perovskite Solar Cells with White Light Illumination Assisted \\ Synthesis
}

Huanqi Cao ${ }^{\#, a}$ Jinzhao Li, ${ }^{\#, a}$ Zheng Dong, ${ }^{a}$ Jie Su, ${ }^{b}$ Jingjing Chang, ${ }^{b,{ }^{*}}$ Qing Zhao ${ }^{c, d}$

Ziyi Li, ${ }^{a}$ Liying Yang, ${ }^{a}$ and Shougen Yin ${ }^{a, *}$

a Key Laboratory of Display Materials and Photoelectric Devices (Ministry of Education), Tianjin Key Laboratory for Photoelectric Materials and Devices \& National Demonstration Center for Experimental Function Materials Education, School of Materials Science and Engineering, Tianjin University of Technology, Tianjin 300384, China

b State Key Discipline Laboratory of Wide Band Gap Semiconductor Technology, School of Microelectronics, Xidian University, 2 South Taibai Road, Xi'an, 710071, China

c State Key Laboratory for Mesoscopic Physics and Electron Microscopy Laboratory, School of Physics, Peking University, Beijing 100871, China

d Collaborative Innovation Center of Quantum Matter, Beijing 100084, China

\section{Experimental details}

MAI was synthesized with a normal method. $\mathrm{MACl}(99.5 \%), \mathrm{CsI}(99.99 \%), \mathrm{PbI}_{2}$ (99.99\%), $\mathrm{PbBr}_{2}$ (99.99\%), PTAA (MN17400) and bathocuproine (BCP, >99\%) were 
purchased from Xi'an p-OLED Corp. $\mathrm{C}_{60}$ (purified by sublimation, Han Feng Chemical), N,N-Dimethylformamide (DMF, J\&K Scientific), and 1,3-Dimethyl-2imidazolidinone (DMI, J\&K Scientific) were used as received without purification.

Etched and cleaned indium tin oxide (ITO) was coated with PTAA by spin-coating $100 \mu \mathrm{L}$ of a PTAA solution ( $2 \mathrm{mg} \mathrm{mL}^{-1}$, toluene) at $5000 \mathrm{rpm}$ for $30 \mathrm{~s}$; the coated substrate was further annealed at $120^{\circ} \mathrm{C}$ for $10 \mathrm{~min} . \mathrm{PbI}_{2}(0.6 \mathrm{~g})$ was dissolved in $\mathrm{DMF}$ (1.3 mol L $\left.{ }^{-1}\right)$ with DMI $(80 \mu \mathrm{L})$, and was further spin-coated at $1000 \mathrm{rpm}$ for $5 \mathrm{~s}$, and $5000 \mathrm{rpm}$ for $30 \mathrm{~s}$. The as-deposited $\mathrm{PbI}_{2}$ adduct films were not annealed before reaction.

On the perovskite formation stage, eight milligrams of MAI were hot-sprayed onto the top plate using ethanol $(8 \mathrm{~mL})$ as the solvent. Further, the parallel hot plates (PHPs) were sealed and evacuated to approximately $650 \mathrm{~Pa}$. Several types of light illumination were introduced from the top transparent top plate, including a green LED/laser, a red LED/laser, a blue LED/laser, a near-infrared LED, and a white LED. The irradiance was $2 \mathrm{~mW} / \mathrm{cm}^{2}$. The bottom plate where the substrates were placed was maintained at $20^{\circ} \mathrm{C}$, whereas the transparent top plate was maintained at $115^{\circ} \mathrm{C}$ for $10 \mathrm{~min}$, during 
which MAI evaporated, transported, and was adsorbed and diffused into the precursor

films. The transparent top plate atop the reference device in each batch was covered with a black cover. The orange-color films were taken out for the ToF-SIMS tests.

Detailed temperatures are in Figure. 2b. For FA-based devices, $\mathrm{CsI}, \mathrm{MACl}$ and $\mathrm{PbBr}_{2}$ were pre-added in the precursor film and FAI was used instead of MAI.

For the complete device fabrication, the reaction was continued as follows. The bottom plate was then heated to $110{ }^{\circ} \mathrm{C}$ for $10 \mathrm{~min}$ to remove remnant solvent molecules, during which the film's color became brown. Both plates were then heated to $120^{\circ} \mathrm{C}$ and were maintained at this temperature for $60 \mathrm{~min}$. Subsequently, Ar was purged into the chamber and the films were transferred to an Ar-filled glove box. Finally, $\mathrm{C}_{60}(20 \mathrm{~nm}), \mathrm{BCP}(8 \mathrm{~nm})$, and $\mathrm{Ag}(100 \mathrm{~nm})$ were sequentially thermally evaporated in a vacuum chamber.

\section{Characterizations}

The elemental depth profiles of perovskite films were performed using X-ray

photoelectron spectroscopy (XPS, Thermo Scientific, ESCALAB250XI). The test 
conditions were: Al K-Alpha with a $500 \mu \mathrm{m}$ diameter and a total acquisition time of 68

s. Time-of-Flight Secondary Ion Mass Spectrometer (ToF-SIMS, iontof 5) data were obtained by sputtering a $170 \times 170 \mu \mathrm{m}^{2}$ square with $\mathrm{O}^{+}$ions $(0.5 \mathrm{keV}, 100 \mathrm{nA})$ under a background pressure of about $1.1 \times 10^{-9} \mathrm{mbar}$. An area of $133 \times 133 \mu \mathrm{m}^{2}$ was analyzed using $\mathrm{Bi}^{+}$ions $(15 \mathrm{keV}, 1 \mathrm{pA})$. A liquid metal $\left(\mathrm{Bi}^{+}\right)$ion gun (LMIG) high current spectrometry was used for inorganic profiling. Before measurements, the films were maintained at $0{ }^{\circ} \mathrm{C}$ in the dark to suppress ionic diffusion.

The in-situ resistance was monitored using a multimeter controlled by a computer.

Details was discussed in our previous works. ${ }^{1,2}$ A programmed Keithley 2400 sourcemeter was used to measure the $J-V$ curves under the illumination of a solar simulator (Newport, AM1.5G, $100 \mathrm{~mW} \mathrm{~cm}^{-2}$ ). The scanning conditions were $1.2 \mathrm{~V} \rightarrow$ $-0.2 \mathrm{~V}$ (reverse) or $-0.2 \mathrm{~V} \rightarrow 1.2 \mathrm{~V}$ (forward), $20 \mathrm{mV}$ per step with a 500 -ms delay. The light source was calibrated with a standard monocrystalline silicon solar cell (SRC1000-TC-QZ, VLSI Standards, Inc.). The measurements were performed in a glovebox filled with Ar. Thickness was measured using a profiler (AlphaStep D-100). XRD (Rigaku Smartlab $9 \mathrm{~kW}$ ) was used to perform structural analysis. A UV-Vis absorption 
spectrophotometer (HP 8453) was used to record the absorption spectra. Spectra of the light sources were measured with a USB2000 spectrometer (Ocean Optics). The surface and cross-sectional morphology was analyzed using scanning electron microscopy (SEM; SU8010, Hitachi). Atomic force microscopy (AFM) was performed using an Innova SPM (Bruker) with a tapping mode. The work function of perovskite films was tested by Kelvin probe measurements (KP Technology KP020). The filling pulse bias of DLTS was $1 \mathrm{~V}$, the measurement bias was $-1 \mathrm{~V}$, and the rate window was $69 \mathrm{~Hz}$.

The voltage at the maximum power point (MPP) of each device was first measured under different light sources with a Zahner photo-electrochemical workstation. The white, red, green, and blue light intensity are $50 \mathrm{~mW} / \mathrm{cm}^{2}, 50 \mathrm{~mW} / \mathrm{cm}^{2}, 40 \mathrm{~mW} / \mathrm{cm}^{2}$, and $50 \mathrm{~mW} / \mathrm{cm}^{2}$, respectively. Then the device was biased at the MPP voltage overnight under the particular illumination. Hall mobility and majority-carrier type of perovskite were tested with a hall-effect measurement system (HMS-505) at r.t., under a 3000/4000/5000 Gs magnetic field with a van der Pauw configuration. Indium was welded as the probes to form Ohmic contacts.

\section{Calculation Method}


Density functional theory (DFT) calculations were carried out, within a projector augmented-wave (PAW) pseudopotentials, as implemented in the Vienna ab initio simulation package (VASP). ${ }^{3-5}$ The generalized gradient approximation (GGA) of Perdew-Burke-Ernzerhof (PBE) without the inclusion of spin-orbit coupling (SOC) ${ }^{6}$ or Heyd-Scuseria-Ernzerhof (HSE) hybrid functional ${ }^{7}$ was adopted to describe the exchange-correlation interactions since the hybrid DFT scheme is not a complete solution to the bandgap and defect transition level problem, meanwhile the defect transition levels of dominated defects obtained by HSE hybrid functional is close to the PBE results. ${ }^{8,9}$ A plane-wave cutoff energy of $400 \mathrm{eV}$ and the k-point sampling at the gamma point were employed. The lattices and atoms were fully relaxed until the maximum residual force on each atom was smaller than $0.01 \mathrm{eV} / \AA$, and the selfconsistent field energy was set to be $10^{-5} \mathrm{eV}$. Migration mediated by defects was examined using nudged elastic band and constrained energy minimization methods. ${ }^{5}$ To obtain the natural physical properties of point defects in $\mathrm{MAPbI}_{3}$ with tetragonal structure, a $2 \times 2 \times 1$ supercell was built up for the defect formation energy and gap levels calculations, and a $4 \times 4 \times 2$ supercell was selected for the defect migration calculations. 
The calculations of defect formation energies and transition levels were described in detail in Supplemental Material. The optimized lattice constants of $\mathrm{MAPbI}_{3}$ tetragonal unit cell were $\mathrm{a}=\mathrm{b}=8.81 \AA$ and $\mathrm{c}=12.68 \AA$, consistent with previous reports. ${ }^{10}$

The defect formation energy $\Delta_{\mathrm{f}} \mathrm{G}$ of a charged defect can be evaluated by the following equation

$$
{ }_{\Delta f} \mathrm{G}=E_{T}(\text { defect, q })-E_{T}(\text { perfect })-\sum n_{i}\left(\mu_{i}+\mu_{i}^{b u l k}\right)+q\left(\varepsilon_{V B M}+E_{f}\right)+\Delta E_{c o r r}
$$

where $E_{T}($ defect, q) indicates the total energy calculated from the supercell with defects in the charge states $\mathrm{q}$ and $E_{T}$ (perfect) is the total energy of supercell without any defects. $n_{i}$ is the number of atoms added $\left(n_{i}<0\right)$ or removed $\left(n_{i}>0\right)$ from the supercell. $\mu_{i}$ is the chemical potential of the relevant atom relative to its bulk chemical potential $\mu_{i}^{b u l k} . \varepsilon_{V B M}$ is the energy of valence band maximum of the defect-free material and $E_{f}$ is the Fermi energy referenced to $\varepsilon_{V B M}$. The $\Delta E_{c o r r}$ is a potential-alignment correction term to correct the finite-size effects in the calculations of charged defects. In addition, to exclude the possible secondary phases $\mathrm{PbI}_{2}$ and $\mathrm{CH}_{3} \mathrm{NH}_{3} \mathrm{I}$, the chemical potentials should be satisfied with the following constraints. 


$$
\begin{gathered}
\mu_{\mathrm{CH}_{3} \mathrm{NH}_{3}}+\mu_{\mathrm{Pb}}+3 \mu_{I}=\Delta H\left(\mathrm{CH}_{3} \mathrm{NH}_{3} \mathrm{PbI}_{3}\right) \\
\mu_{\mathrm{CH}_{3} \mathrm{NH}_{3}}+\mu_{I}<\Delta H\left(\mathrm{CH}_{3} \mathrm{NH}_{3} \mathrm{I}\right) \\
\mu_{P b}+2 \mu_{I}<\Delta H\left(\mathrm{PbI}_{2}\right)
\end{gathered}
$$

where $\mathrm{AH}\left(\mathrm{CH}_{3} \mathrm{NH}_{3} \mathrm{PbI}_{3}\right), \Delta \mathrm{H}\left(\mathrm{CH}_{3} \mathrm{NH}_{3} \mathrm{I}\right)$, and $\mathrm{PbI}_{2}$ are the formation enthalpies of $\mathrm{CH}_{3} \mathrm{NH}_{3} \mathrm{PbI}_{3}, \mathrm{CH}_{3} \mathrm{NH}_{3} \mathrm{I}$, and $\mathrm{PbI}_{2}$, respectively.

The transition energy level between two charge states $\mathrm{q}$ and $\mathrm{q}^{\prime}\left[v i z . \varepsilon_{a}\left(\mathrm{q} / \mathrm{q}^{\prime}\right)\right]$ can be defined as the value of Fermi level where the formation energy of q equals to that of q' of the same defect, i.e.,

$$
\varepsilon_{a}\left(q / q^{\prime}\right)=\left[\Delta f \mathrm{G}(\mathrm{q})-\Delta f \mathrm{G}\left(q^{\prime}\right)\right] /\left(q^{\prime}-\mathrm{q}\right)
$$

When the Fermi level is lower than this energy, the charge state q is stable; otherwise, the charge state $\mathrm{q}^{\prime}$ is stable.

According to the equations (S-2) - (S-4), the phase diagram of stable $\mathrm{CH}_{3} \mathrm{NH}_{3} \mathrm{PbI}_{3}$ involved in the chemical potentials of $\mathrm{Pb}$ and I elements are obtained and shown in Figure S17. The chemical potential of I atom $\left(\mu_{I}\right)$ ranges from $0 \mathrm{eV}$ to $-1.19 \mathrm{eV}$. The representative point A (I-rich condition, $\mu_{I}=0 \mathrm{eV}, \mu_{P b}=-2.90 \mathrm{eV}, \mu_{M A}=-2.27 \mathrm{eV}$ ) 
and B (I-poor condition, $\mu_{I}=-1.19 \mathrm{eV}, \mu_{P b}=0 \mathrm{eV}, \mu_{M A}=-1.60 \mathrm{eV}$ ) have been chosen to calculate the defect formation energy.

Figure S18 displays the defect formation energy as a function of the Fermi level at the I-rich and I-poor conditions. The Fermi levels are referenced to the valence band maximum (VBM) of $\mathrm{CH}_{3} \mathrm{NH}_{3} \mathrm{PbI}_{3}$, and the position of intrinsic Fermi level is the zero point. Since the calculated band gap of $\mathrm{CH}_{3} \mathrm{NH}_{3} \mathrm{PbI}_{3}$ is about $1.53 \mathrm{eV}$, thus the Fermi level can vary from $0 \mathrm{eV}$ to $1.53 \mathrm{eV}$. From Fig. $\mathrm{S} 19$, the P-type defects $\left(\mathrm{V}_{\mathrm{Pb}}, \mathrm{I}_{\mathrm{MA}}, \mathrm{I}_{\mathrm{Pb}}\right.$, $\mathrm{V}_{\mathrm{MA}}$, and $\mathrm{I}_{\mathrm{i}}$ ) show the lowest defect formation energies when the $E_{\mathrm{f}}$ near CBM (viz. $E_{\mathrm{f}}$ $=1.53 \mathrm{eV})$, while $\mathrm{N}$-type defects $\left(\mathrm{Pb}_{\mathrm{I}}, \mathrm{V}_{\mathrm{I}}\right.$, and $\left.\mathrm{P}_{\mathrm{bi}}\right)$ exhibit the lowest defect formation energies when the $E_{\mathrm{f}}$ near the $\mathrm{VBM}\left(\right.$ viz. $E_{\mathrm{f}}=0 \mathrm{eV}$ ). The lowest formation energies of the P-type (when $\left.E_{\mathrm{f}}=1.53 \mathrm{eV}\right)$ and N-type $\left(E_{\mathrm{f}}=0 \mathrm{eV}\right)$ defects are listed in Table 2, which are close to other reported values. ${ }^{11-13}$ Meanwhile, the charge states of the most stable $\mathrm{V}_{\mathrm{Pb}}, \mathrm{I}_{\mathrm{MA}}, \mathrm{I}_{\mathrm{Pb}}, \mathrm{V}_{\mathrm{MA}}, \mathrm{I}_{\mathrm{i}}, \mathrm{Pb}_{\mathrm{I}}, \mathrm{V}_{\mathrm{I}}$, and $\mathrm{P}_{\mathrm{bi}}$ are $-2,-2,-3,-1,-1,+3,+1$, and +2 , respectively.

Figure S19 displays transition energy levels for the selected eight different defects in $\mathrm{CH}_{3} \mathrm{NH}_{3} \mathrm{PbI}_{3}$. Several transition energy levels maybe induced by the same one defect 
since the defect may possess several charge states. According to Figure S18, the charge states of the most stable $\mathrm{V}_{\mathrm{Pb}}, \mathrm{I}_{\mathrm{MA}}, \mathrm{I}_{\mathrm{Pb}}, \mathrm{V}_{\mathrm{MA}}, \mathrm{I}_{\mathrm{i}}, \mathrm{Pb}_{\mathrm{I}}, \mathrm{V}_{\mathrm{I}}$, and $\mathrm{P}_{\mathrm{bi}}$ are $-2,-2,-3,-1,-1,+3$, +1 , and +2 , respectively. Hence, the most likely transition energy levels of $\mathrm{V}_{\mathrm{Pb}}, \mathrm{I}_{\mathrm{MA}}$, $\mathrm{I}_{\mathrm{Pb}}, \mathrm{V}_{\mathrm{MA}}, \mathrm{I}_{\mathrm{i}}, \mathrm{Pb}_{\mathrm{I}}, \mathrm{V}_{\mathrm{I}}$, and $\mathrm{P}_{\mathrm{bi}}$ are 1-/2-, 1-/2-, 2-/3-, 0/1-, 0/1-, 3+/1+, 1+/0, and 2+/1+, respectively, as marked by the bold horizontal lines. In general, the transition energy level reflects the defect gap level induced by the corresponding defect. Moreover, the transition energy levels induced by N-type defects are close to the VBM, the transition energy levels induced by P-type defects are close to the CBM. Hence, defect gap states of P-type defects $\mathrm{V}_{\mathrm{Pb}}, \mathrm{I}_{\mathrm{MA}}, \mathrm{I}_{\mathrm{Pb}}, \mathrm{V}_{\mathrm{MA}}$, and $\mathrm{I}_{\mathrm{i}}$ reference to the $\mathrm{VBM}$ are $0.25 \mathrm{eV}, 0.62 \mathrm{eV}$, $0.81 \mathrm{eV}, 0 \mathrm{eV}, 0.07 \mathrm{eV}$, respectively; defect gap states of N-type defects $\mathrm{Pb}_{\mathrm{I}}, \mathrm{V}_{\mathrm{I}}$, and $\mathrm{Pb}_{\mathrm{i}}$ reference to the $\mathrm{CBM}$ are $0.52 \mathrm{eV}, 0.09 \mathrm{eV}, 0.48 \mathrm{eV}$, respectively, as listed in Table 2. 
(a)

$10 \mathrm{~mW} \mathrm{~cm} \mathrm{~cm}^{-2} 2 \mathrm{~mW} \mathrm{~cm} \mathrm{~cm}^{-2} 0.4 \mathrm{~mW} \mathrm{~cm}^{-2}$

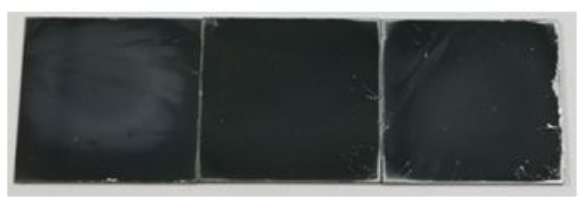

(c)

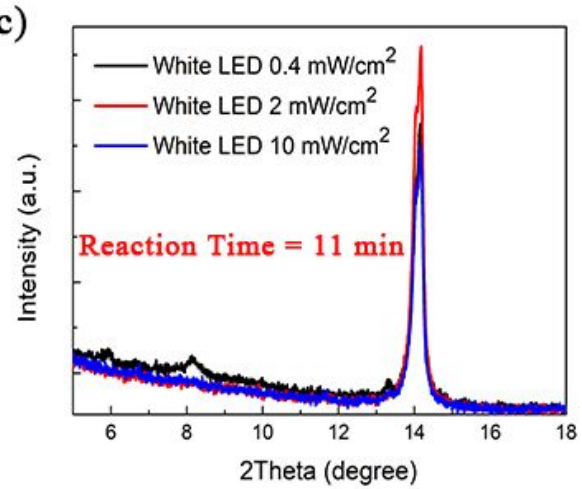

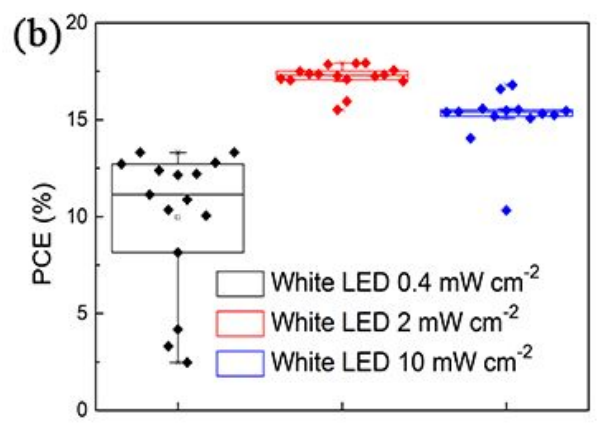

(d)

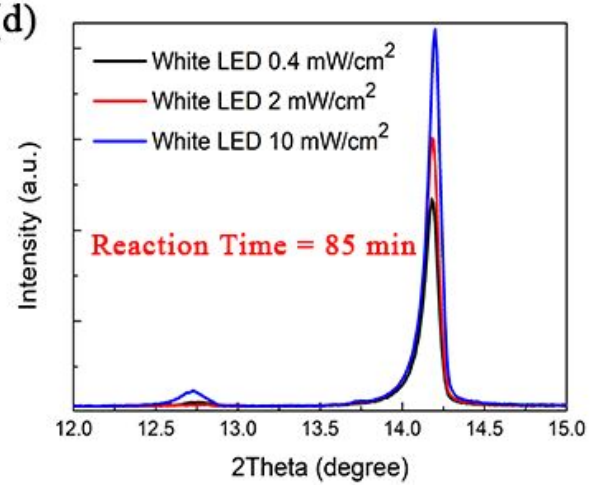

Fig. S1 Perovskite films prepared under white illumination of different intensities: (a) photographs; (b) efficiency box chart for the devices. The $0.4 \mathrm{~mW} / \mathrm{cm}^{2}$ and 10 $\mathrm{mW} / \mathrm{cm}^{2}$ samples are hazy on the surface and their device efficiency is relatively low. XRD patterns of perovskite films reacted in (c) $11 \mathrm{~min}$ (low-crystallized samples) and (d) $80 \mathrm{~min}$ (highly-crystallized samples). Among the low-crystallized perovskite, the $0.4 \mathrm{~mW} / \mathrm{cm}^{2}$ sample exhibits strong $\mathrm{PbI}_{2}$ adduct peak at $8.1^{\circ}$, suggesting an incomplete diffusion of MAI under such a low irradiance. Among the highlycrystallized samples, the $10 \mathrm{~mW} / \mathrm{cm}^{2}$ sample exhibits a relatively higher $\mathrm{PbI}_{2}$ peak at $12.7^{\circ}$, indicating the illumination's heating effect decomposes as-synthesized perovskite. 


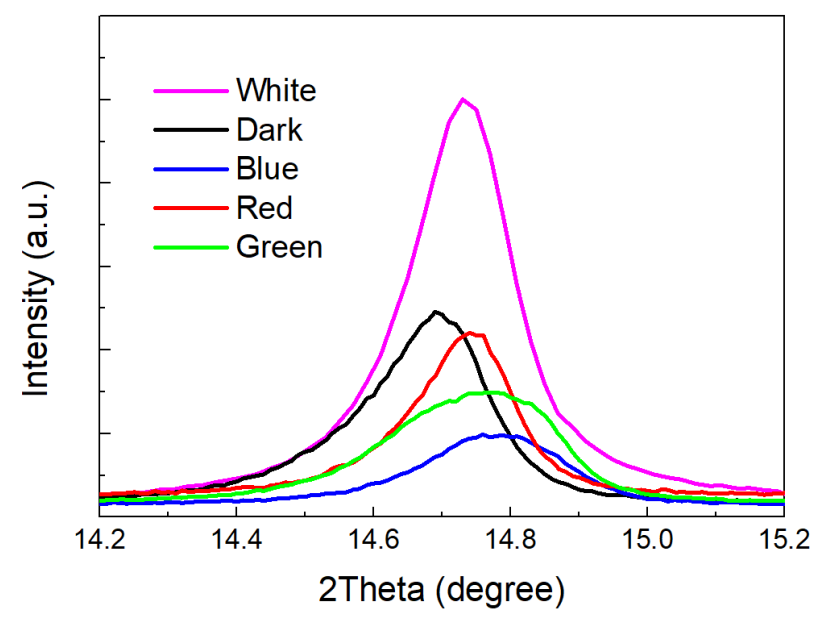

Fig. S2 XRD patterns of perovskite films used for ToF-SIMS tests.

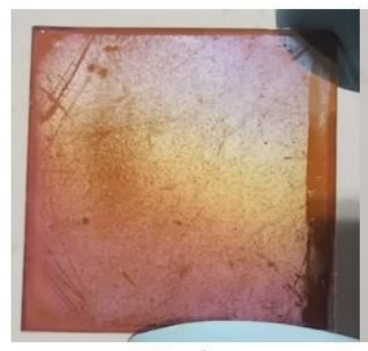

Dark

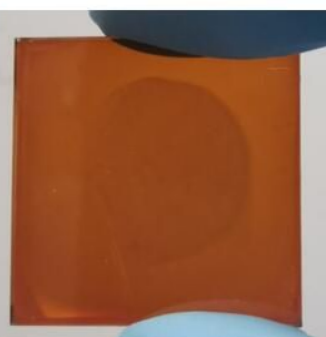

Green

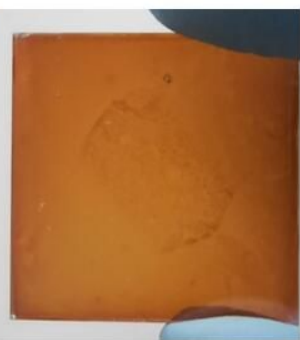

Red

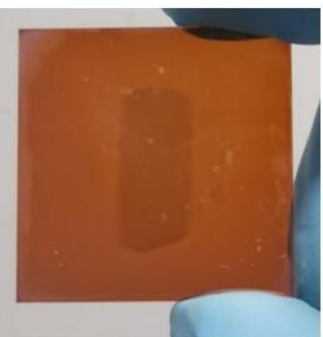

Blue

Fig. S3 Photographs of the perovskite films used for ToF-SIMS tests. The central spots are the laser spots' shape. 


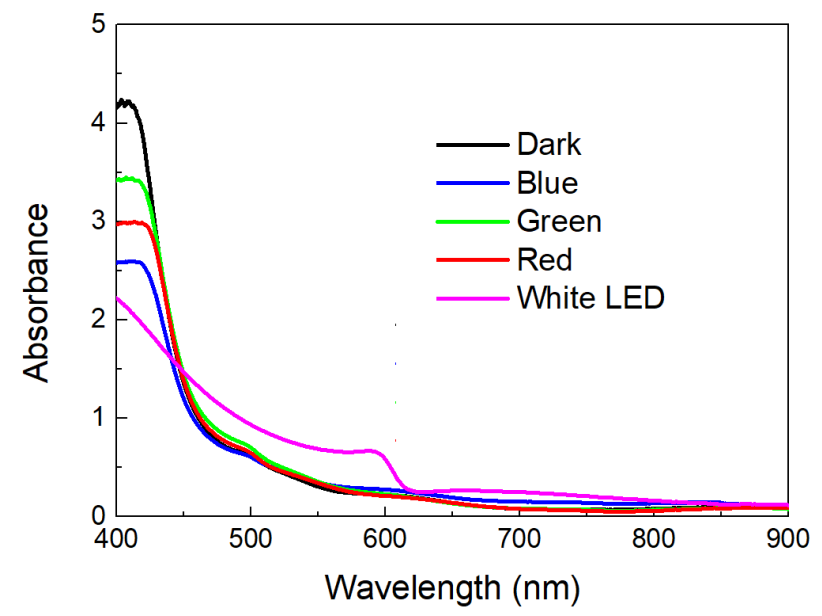

Fig. S4 Absorption spectra of perovskite films used for ToF-SIMS tests.

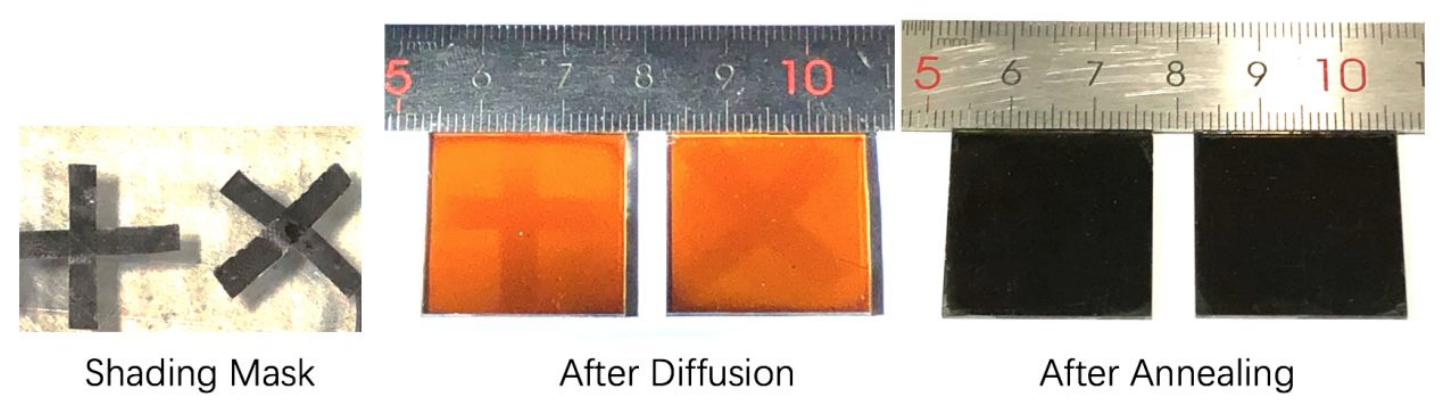

Fig. S5 Left: Several pieces of black tape were used as the mask to shade the incident white light during the synthesis of perovskite. Middle: The same pattern was formed on the WIA film after 10 mins' diffusion. Right: a uniform perovskite film was formed after the following annealing step; the pattern disappeared. Note that the same mask was used during the entire process. 


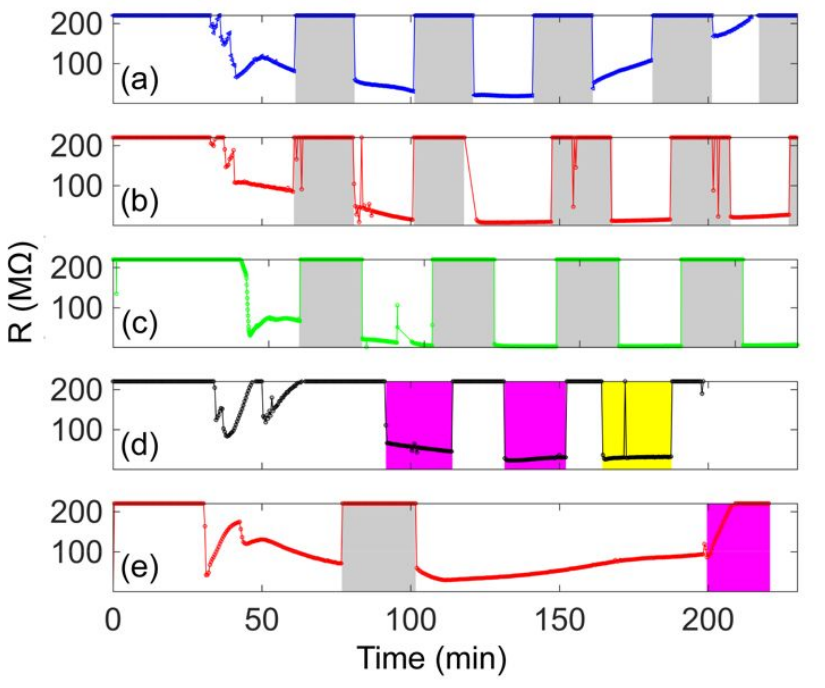

Fig. S6 In-situ measured resistance of perovskite films under different light illuminations, a: blue, b: red, c: green, d: dark and e: red. In the grey periods, the film was kept in the dark while in the magenta periods, the film was exposed under white light. The MAI vapor in the chamber was nearly exhausted in the chamber after about 120 min. During the yellow period in fig. $d$, the film was exposed under white light and Ar was purged into the chamber. For others the chamber was in a vacuum. The white illumination and heating on crystallized perovskite in Ar did not decrease the intrinsic resistance to the measurable range, suggesting the role of white illumination is important mainly in the diffusion step. Without enough MAI supply, the synergistic effect of white illumination and heating in vacuum decomposed the RIA perovskite, as shown by the increase of electric resistance in fig. e. 
(a)

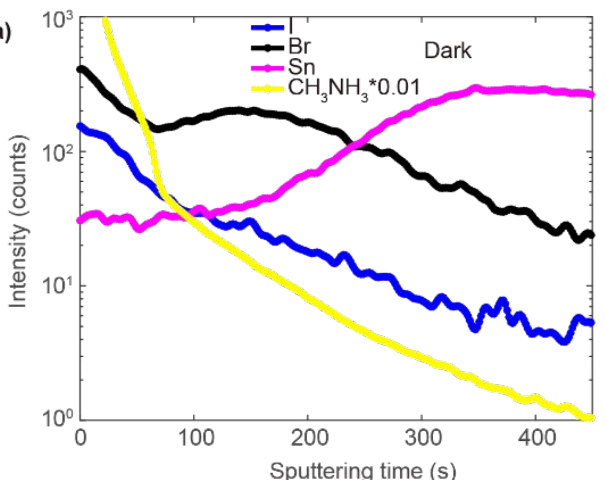

(c)

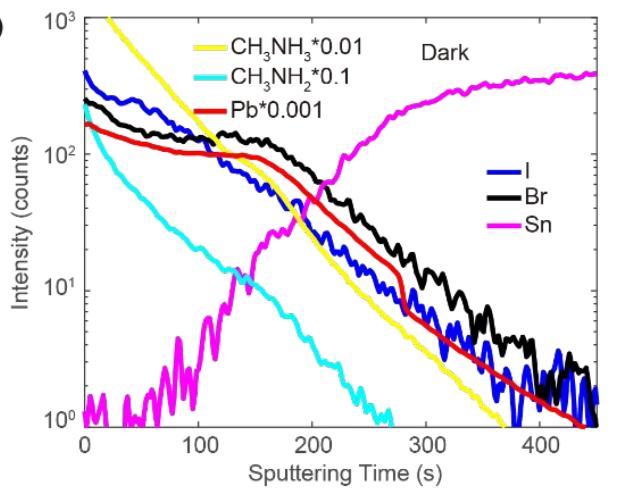

(e)

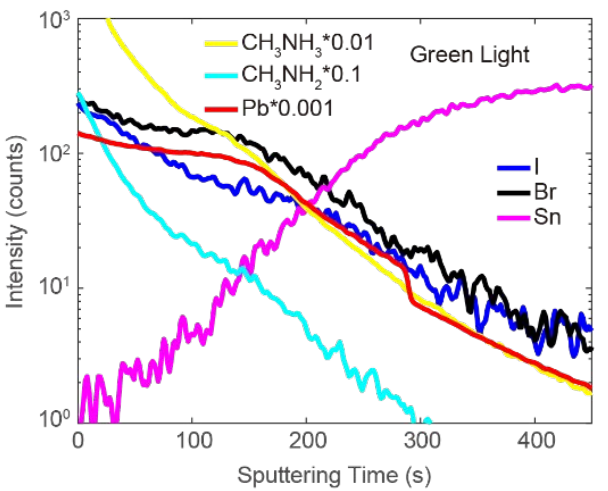

(g)

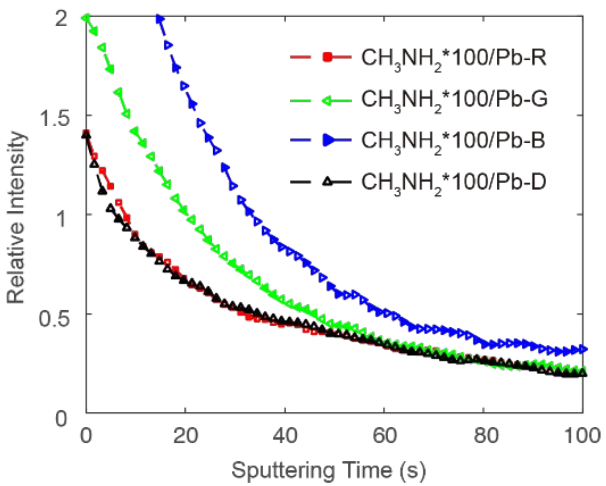

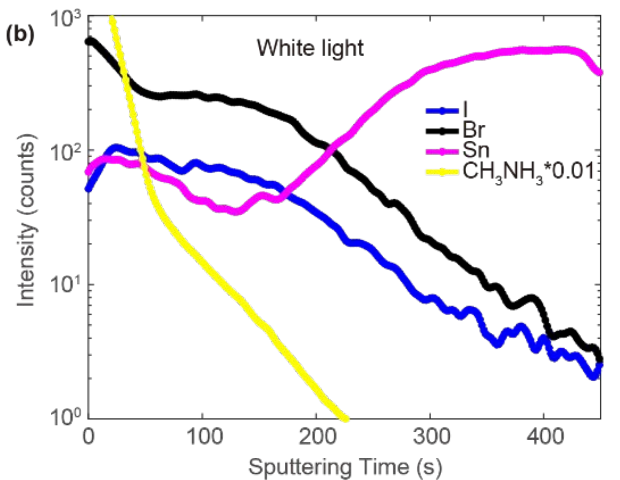
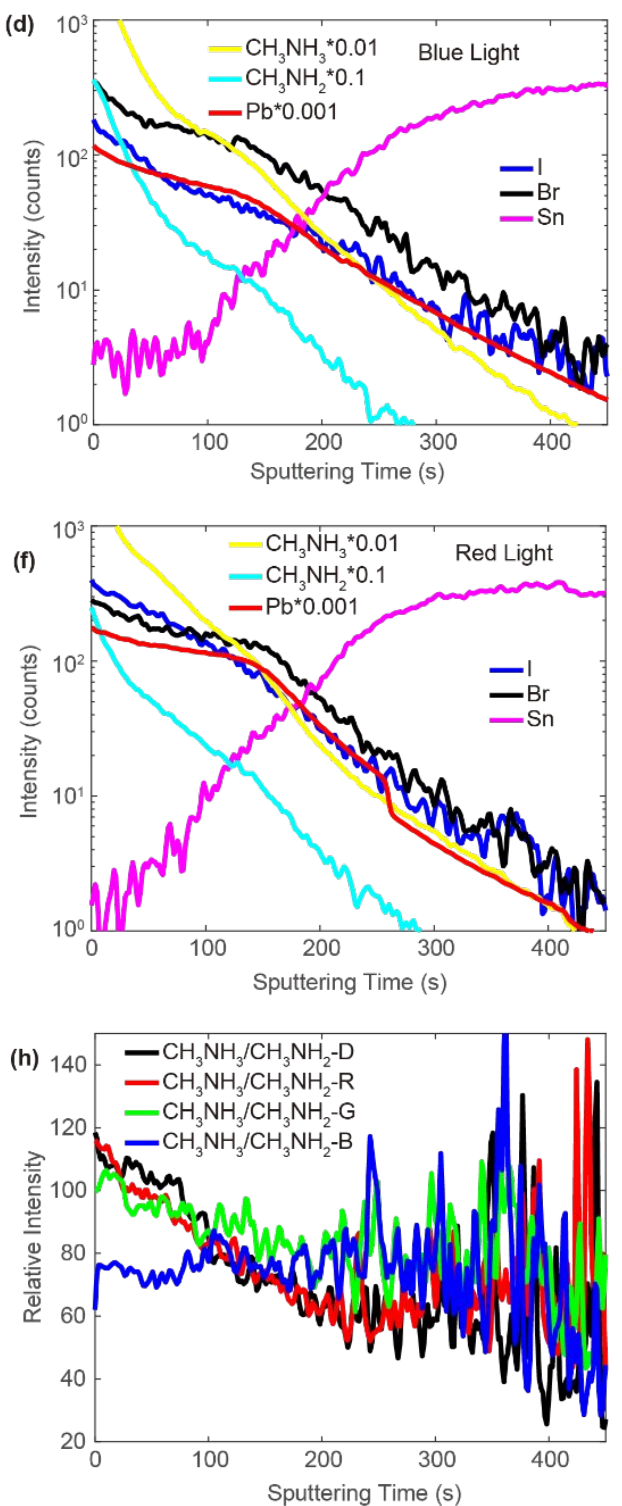

Fig. S7 ToF-SIMS depth profiles of characteristic ions in perovskite prepared under different illuminations (a-f). Comparison of the relative intensities between $\mathrm{CH}_{3} \mathrm{NH}_{2}$ and $\mathrm{Pb}(\mathrm{g})$, or between $\mathrm{CH}_{3} \mathrm{NH}_{3}$ and $\mathrm{CH}_{3} \mathrm{NH}_{2}(\mathrm{~h})$. 


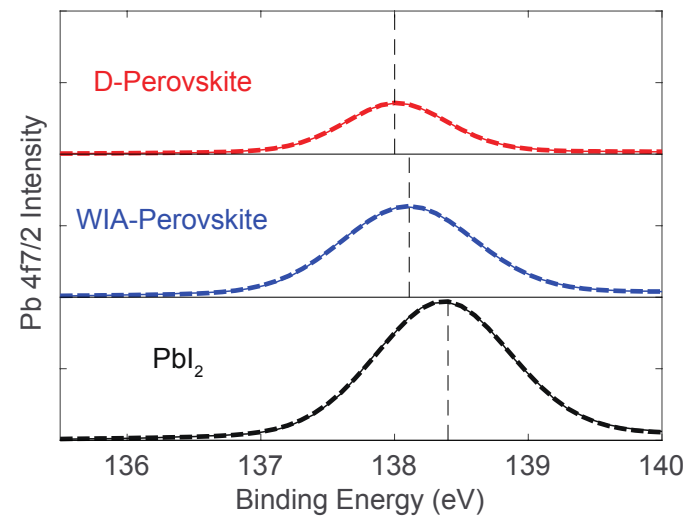

Fig. S8 XPS signals and fitting results. All curves can be perfectly fitted with a single Voigt function. The center positions are located in the range of $138.0-138.4 \mathrm{eV}$, which can be assigned to $\mathrm{Pb}^{2+} 4 \mathrm{f} / 2$ in either perovskite or $\mathrm{PbI}_{2}$.

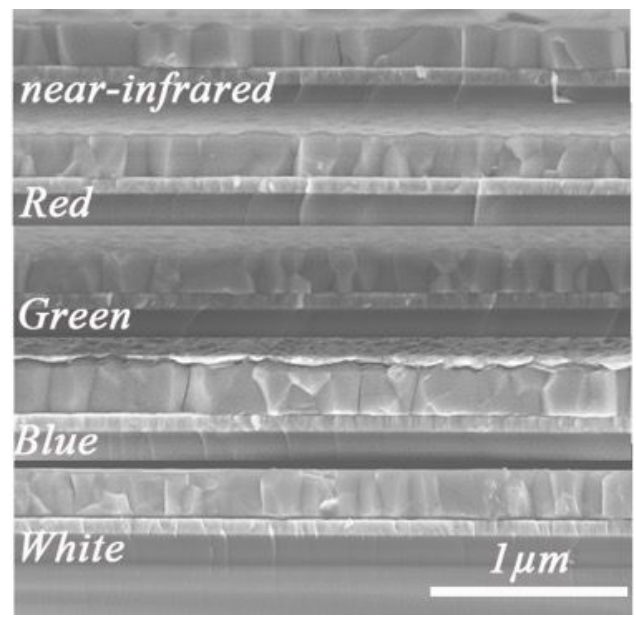

Fig. S9 Cross-sectional SEM images of perovskite films prepared under different illumination conditions. 

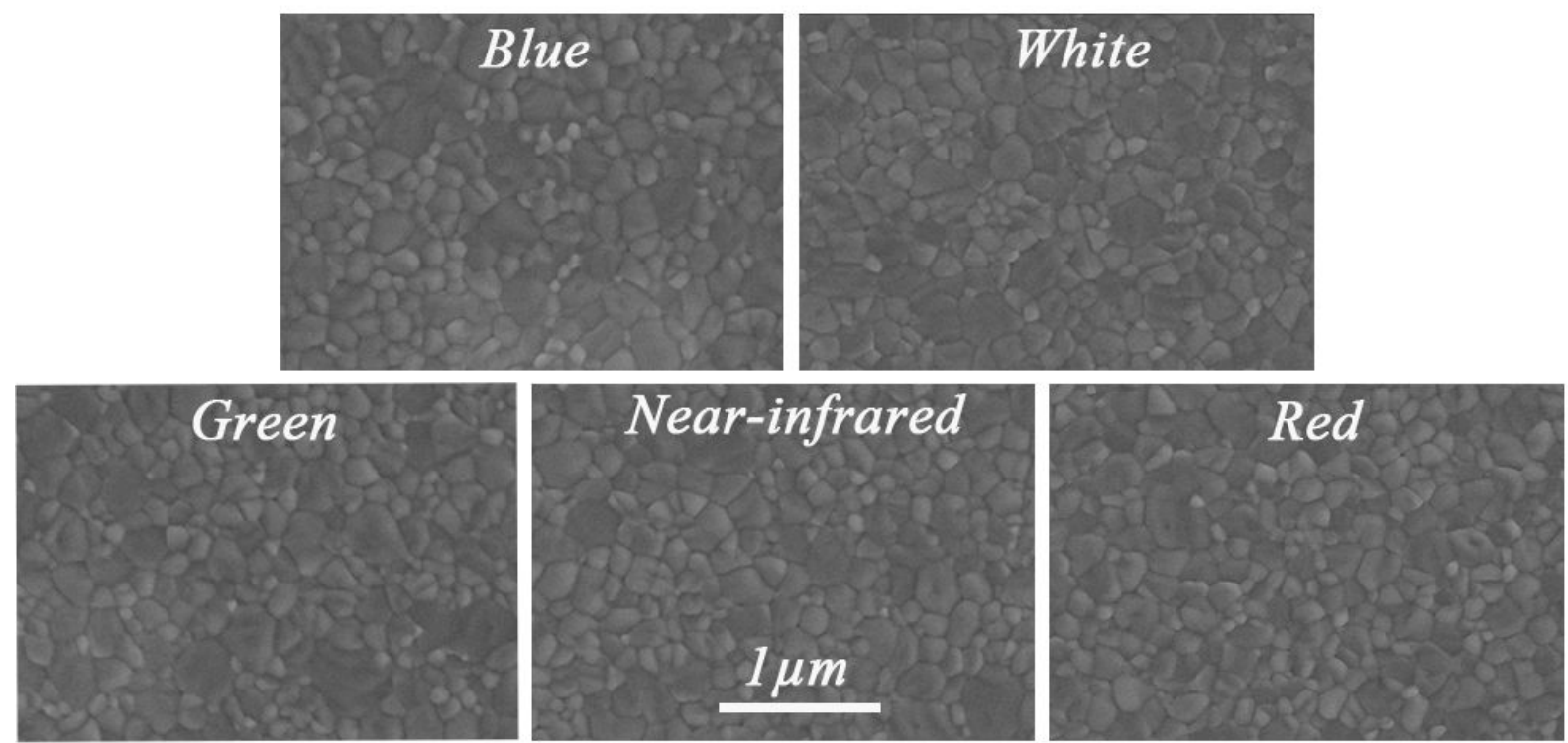

Fig. S10 SEM images of perovskite films prepared under different illumination conditions.

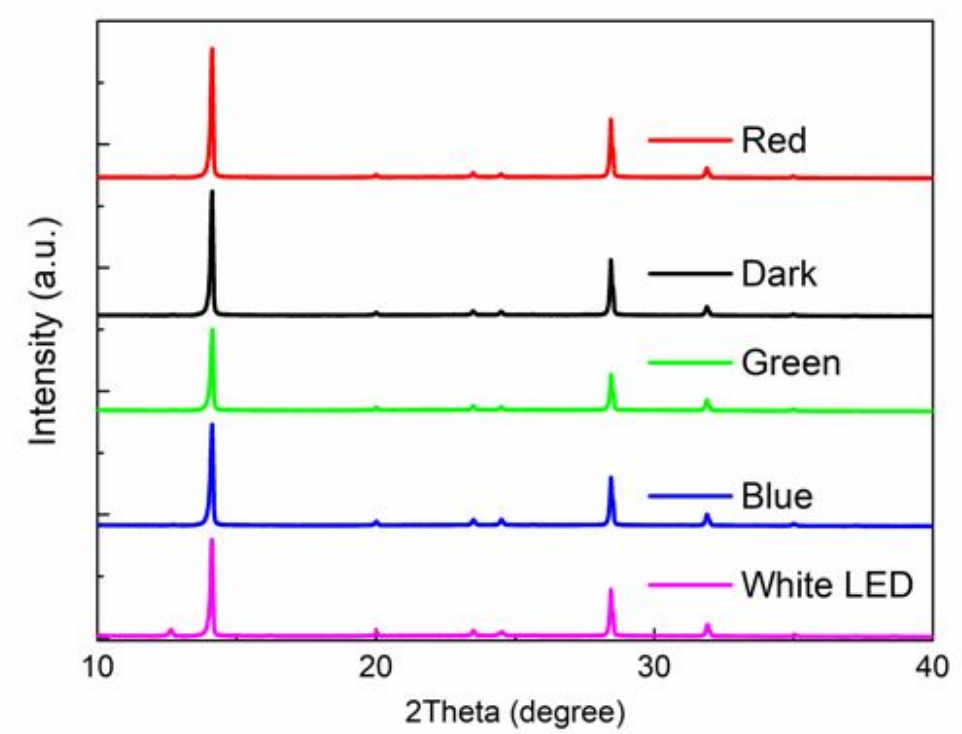

Fig. S11 XRD results of red, green, blue, white, and dark samples. 


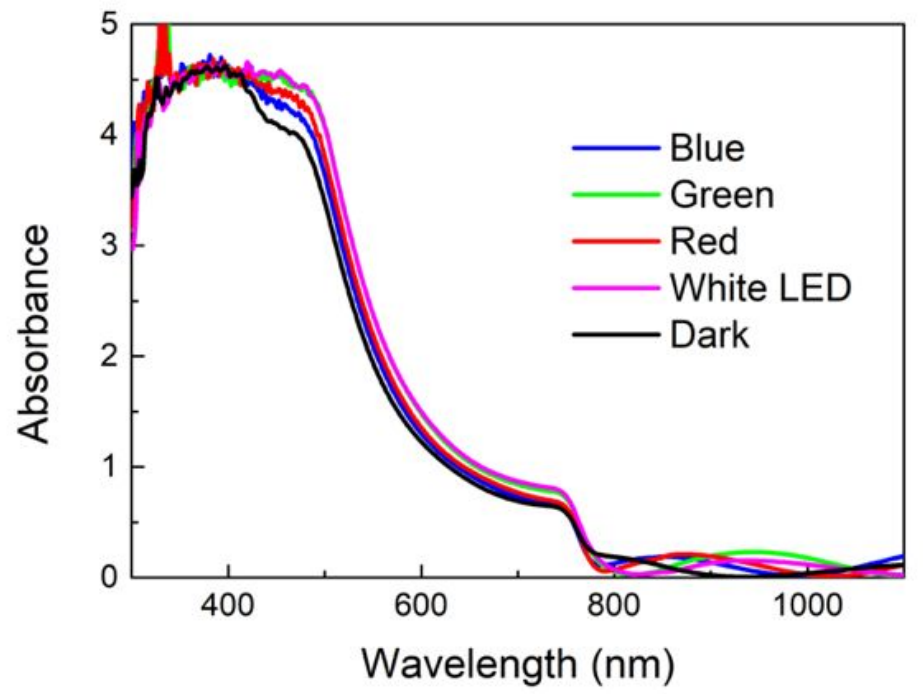

Fig. S12 UV-vis absorbance curves of blue, green, red, white, and dark samples.

Table S1 The Hall-effect measurement results of a WIA perovskite film.

\begin{tabular}{|c|c|c|c|}
\hline $\begin{array}{l}\text { Field } \\
\text { (Gs) }\end{array}$ & $\begin{array}{c}\text { Carrier } \\
\text { concentration } \\
\left(\mathrm{cm}^{-3}\right)\end{array}$ & $\begin{array}{l}\text { Mobility } \\
\left(\mathrm{cm}^{2} / \mathrm{V} / \mathrm{s}\right)^{\mathrm{a}}\end{array}$ & type \\
\hline 3000 & $1.01 \mathrm{E} 13$ & 249.36 & $\mathrm{p}$ \\
\hline 4000 & $0.99 \mathrm{E} 13$ & 339.17 & $\mathrm{p}$ \\
\hline 5000 & $0.99 \mathrm{E} 13$ & 255.78 & $\mathrm{p}$ \\
\hline
\end{tabular}

a: The values might be overestimated. 


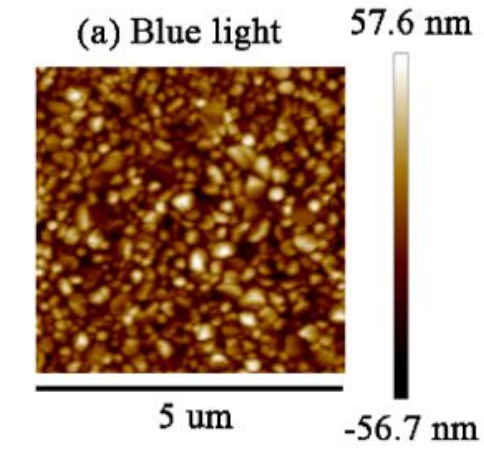

(b) White LED $55.2 \mathrm{~nm}$

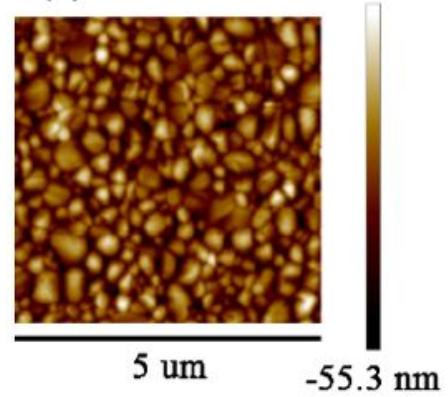

(c) Red light $\quad 54.3 \mathrm{~nm}$

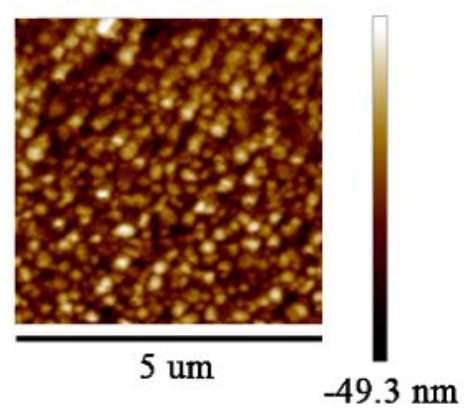

(d) Dark light $68.8 \mathrm{~nm}$

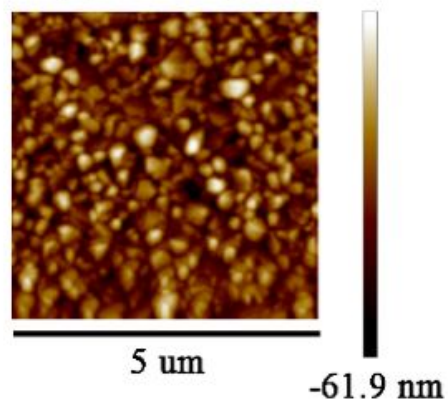

(e) Green light $42.7 \mathrm{~nm}$

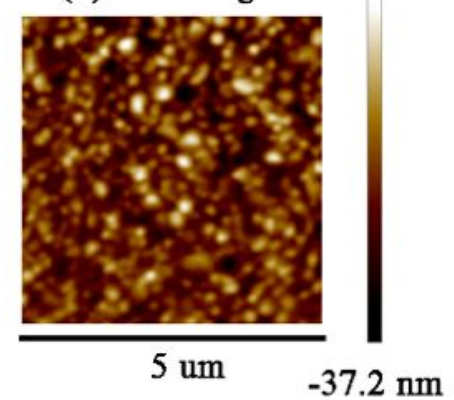

Fig. S13 AFM images of the BIA (a), WIA (b), RIA (c), D (d), and GIA (e) perovskite films. 


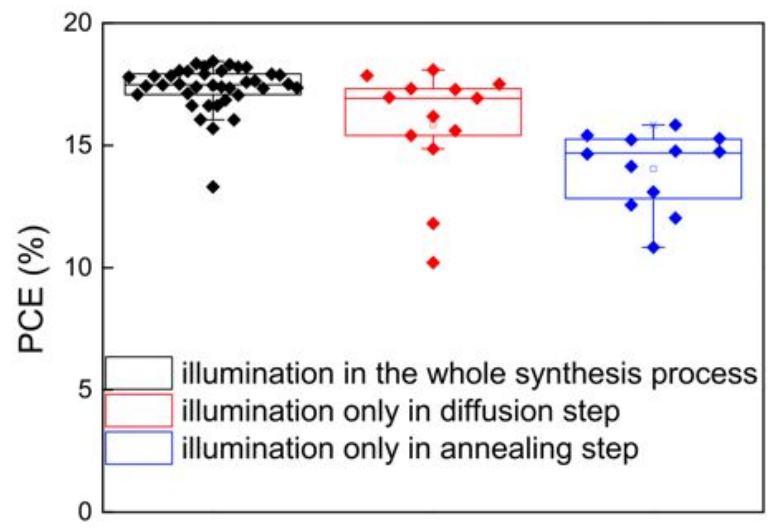

Fig. S14 Box chart of efficiency for the white-illumination-assisted devices. The illumination was applied in the entire synthesis procedure (black), in the first 10 mins' diffusion step (red, corresponding to the A-B region in Figure. $2 \mathrm{~b}$ ) or in the $10-80$ mins' annealing step (blue, B-D region in Figure. 2b).

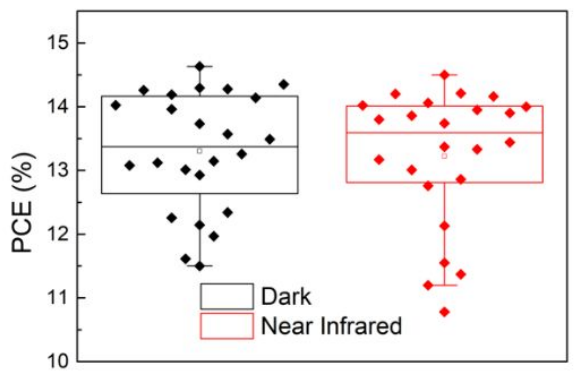

Fig. S15 Box chart of efficiency for the dark, and NIR-illumination-assisted devices. 


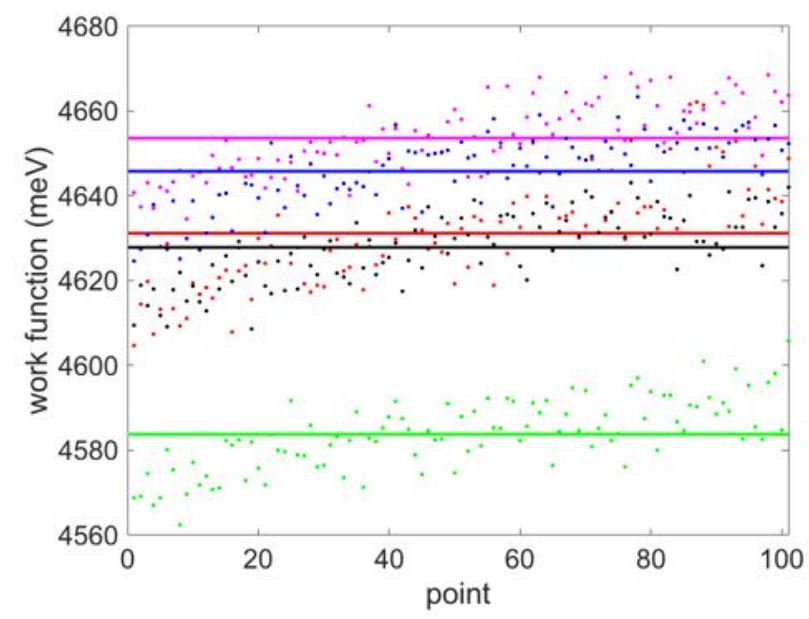

Fig. S16 Work function of perovskite prepared under different light conditions: white (magenta), red (red), blue (blue), dark (black), and green (green). Each data point was obtained by averaging over five measurements. A gold reference with a work function of $5.1 \mathrm{eV}$ was used to calibrate measured data. The WIA sample shows the highest work function of $4.654 \mathrm{eV}$, followed by $4.646 \mathrm{eV}$ for blue, $4.631 \mathrm{eV}$ for red, $4.628 \mathrm{eV}$ for dark, and $4.584 \mathrm{eV}$ for green.
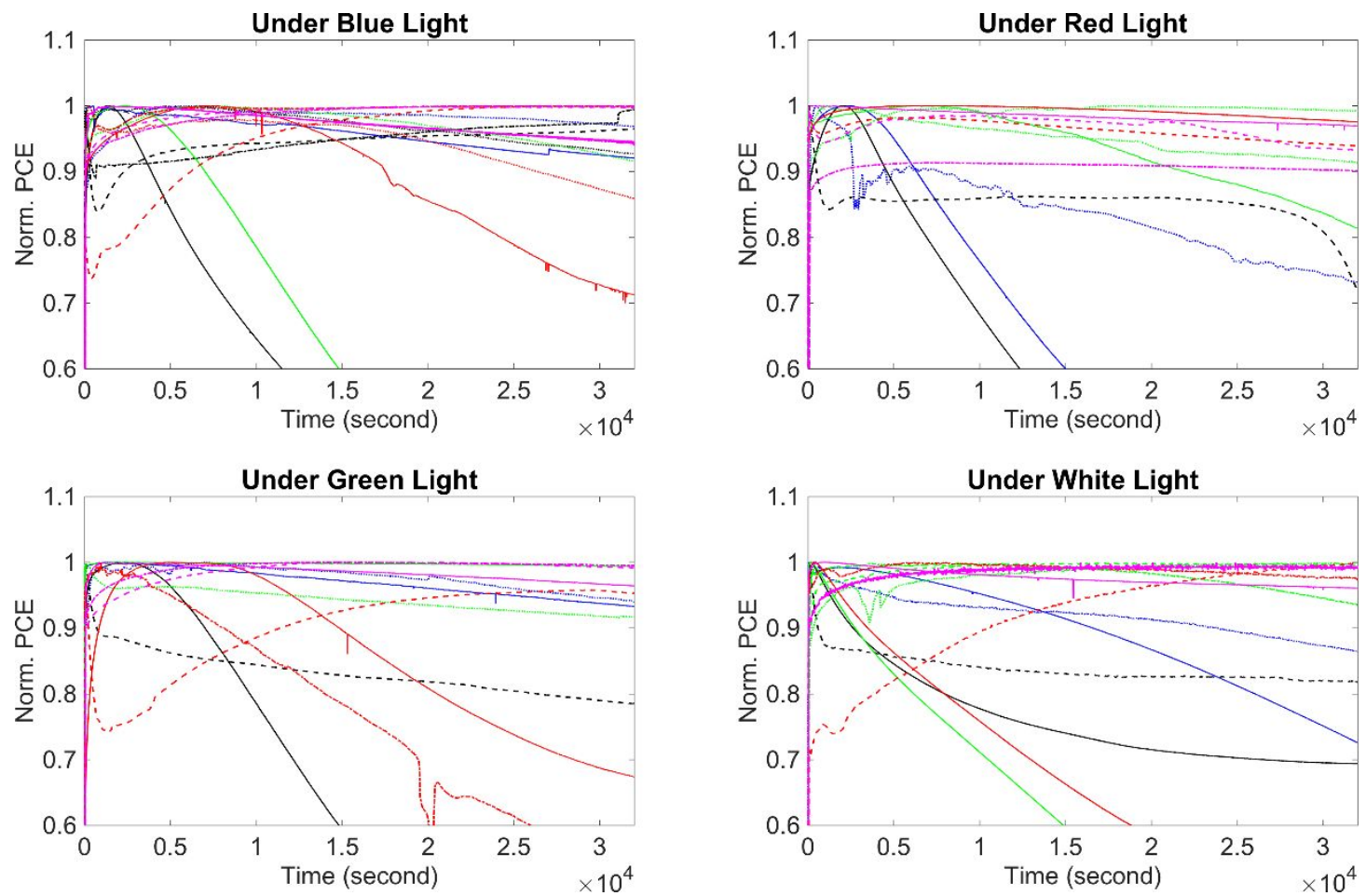

Fig. S17 MPPT results of various devices under different lights. The colors of the curves correspond to the color of light that was used to synthesize the perovskite (magenta for white). 


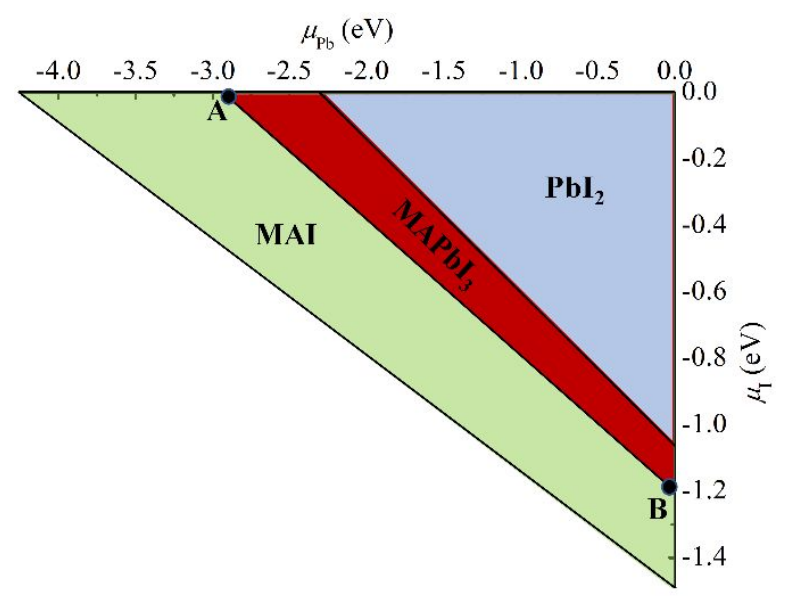

Fig. S18 Calculated phase diagram of stable $\mathrm{CH}_{3} \mathrm{NH}_{3} \mathrm{PbI}_{3}$ involved in the chemical potentials of $\mathrm{Pb}$ and I atoms.
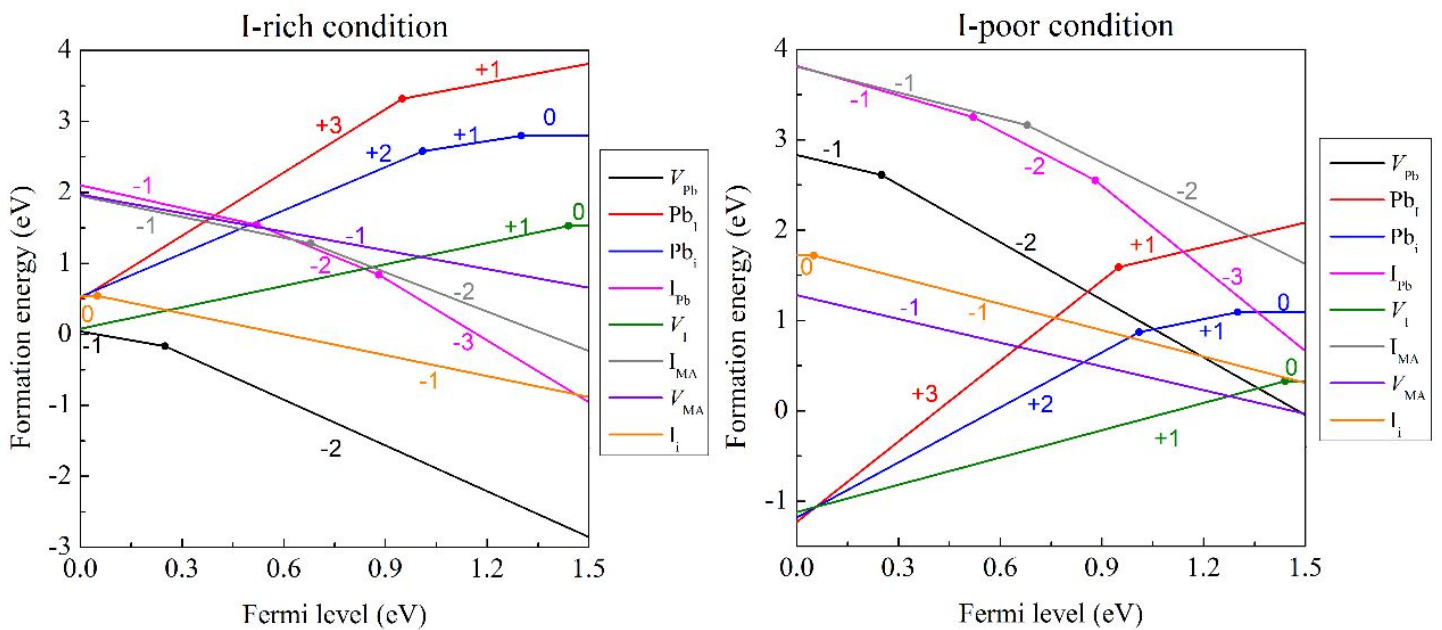

Fig. S19 Calculated defect formation energy as a function of the Fermi level at the chemical potential point A (I-rich condition, $\mu_{I}=0 \mathrm{eV}, \mu_{P b}=-2.90 \mathrm{eV}, \mu_{M A}=-2.27$ $\mathrm{eV}$ ) and $\mathrm{B}$ (I-poor condition, $\mu_{I}=-1.19 \mathrm{eV}, \mu_{P b}=0 \mathrm{eV}, \mu_{M A}=-1.60 \mathrm{eV}$ ), as shown in Fig. S18. 


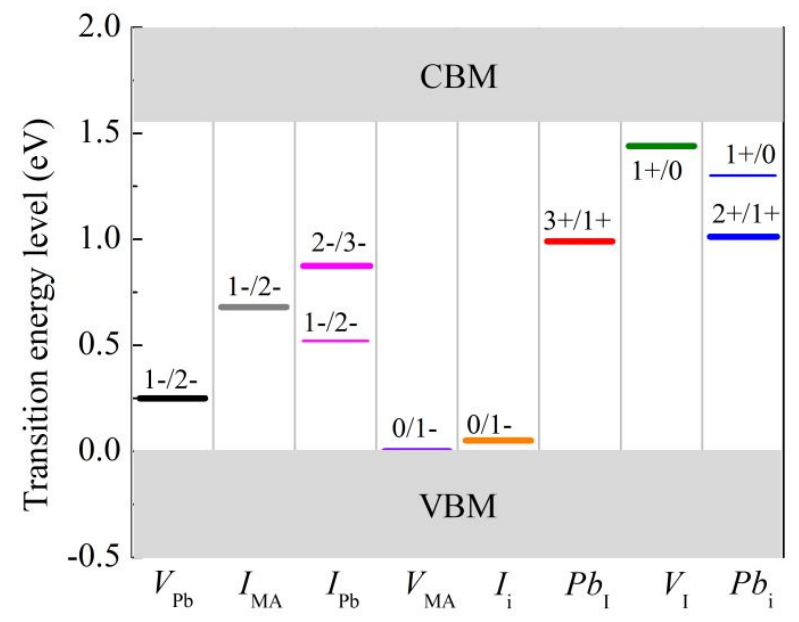

Fig. S20 Calculated transition energy levels $\left(E_{\text {states }}\right)$ for the selected eight different defects in $\mathrm{CH}_{3} \mathrm{NH}_{3} \mathrm{PbI}_{3}$, which are referenced to the $\mathrm{VBM}$ of pure $\mathrm{CH}_{3} \mathrm{NH}_{3} \mathrm{PbI}_{3}$.

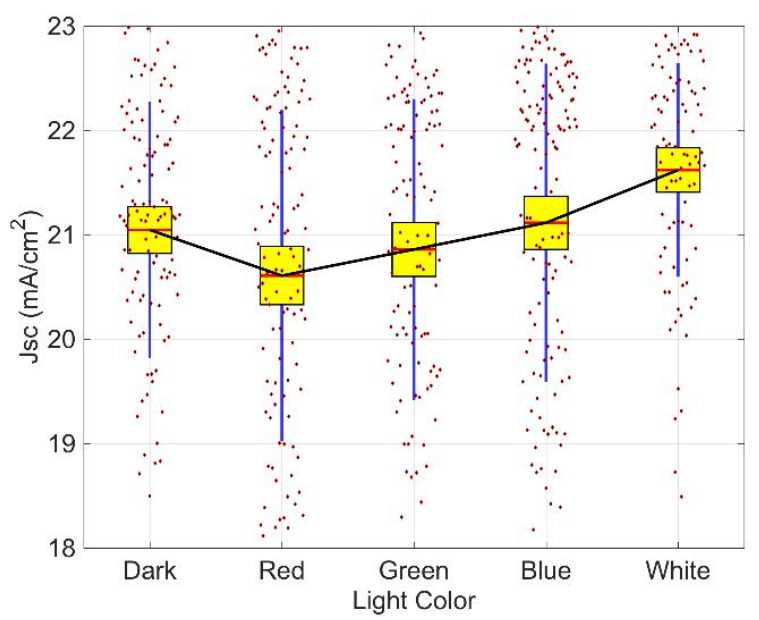

Fig. S21 Box charts of $\mathrm{J}_{\mathrm{SC}}$ of $\mathrm{MAPbI}_{3}$ devices (total number is 584) prepared under different lighting conditions. 


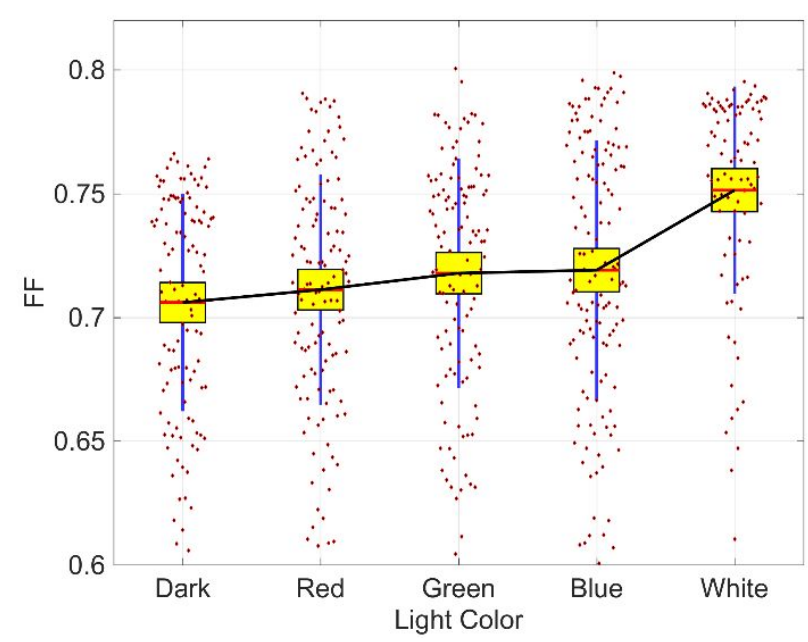

Fig. S22 Box charts of FF of $\mathrm{MAPbI}_{3}$ devices (total number is 584) prepared under different lighting conditions.

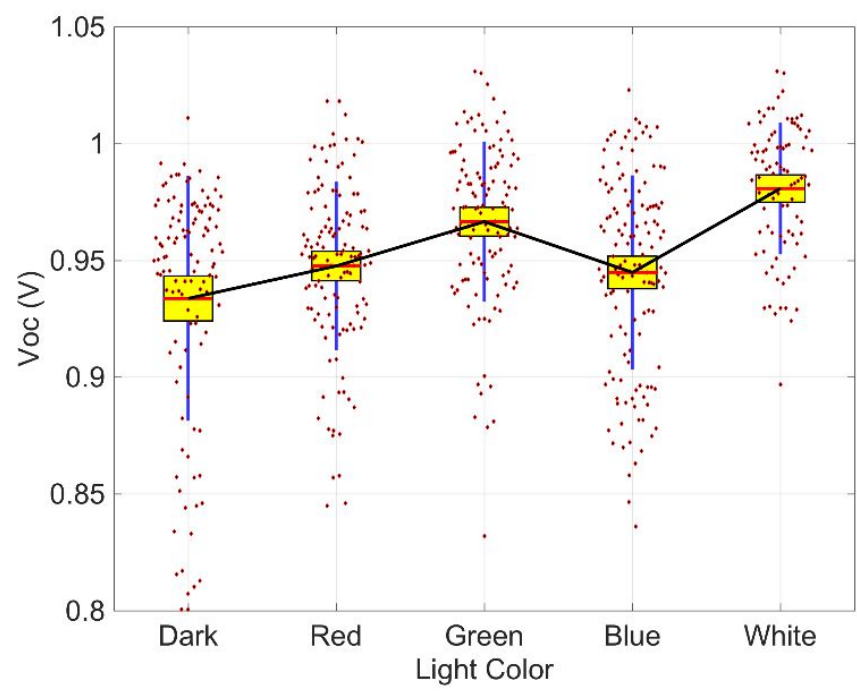

Fig. S23 Box charts of $\mathrm{V}_{\mathrm{OC}}$ of $\mathrm{MAPbI}_{3}$ devices (total number is 584) prepared under different lighting conditions. 

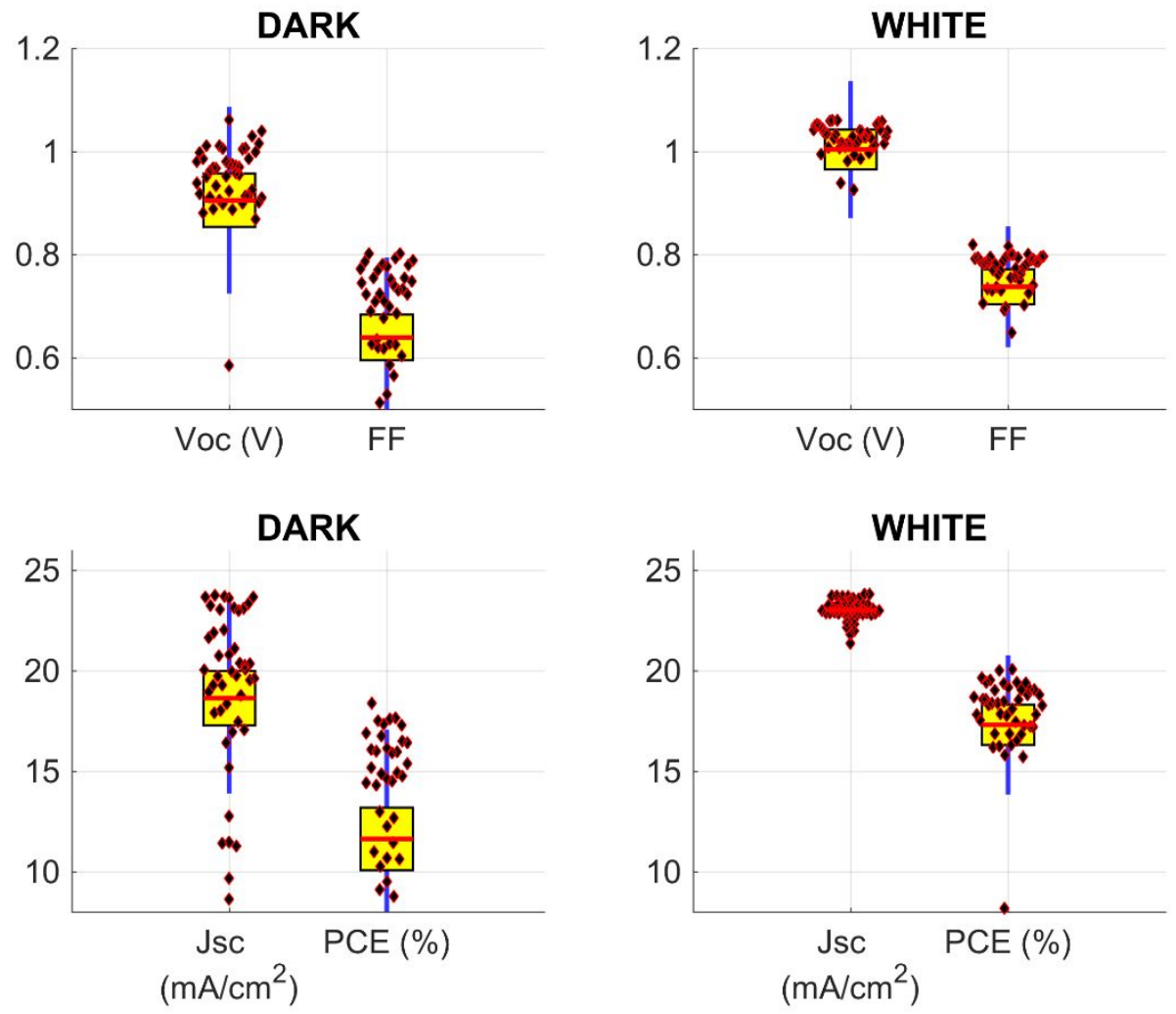

Fig. S24 Box charts of $\mathrm{J}_{\mathrm{SC}}, \mathrm{V}_{\mathrm{OC}}, \mathrm{FF}$ and PCE of FA(CsMA)PbI(Br) $)_{3}$ devices (93 devices) prepared under different lighting conditions.

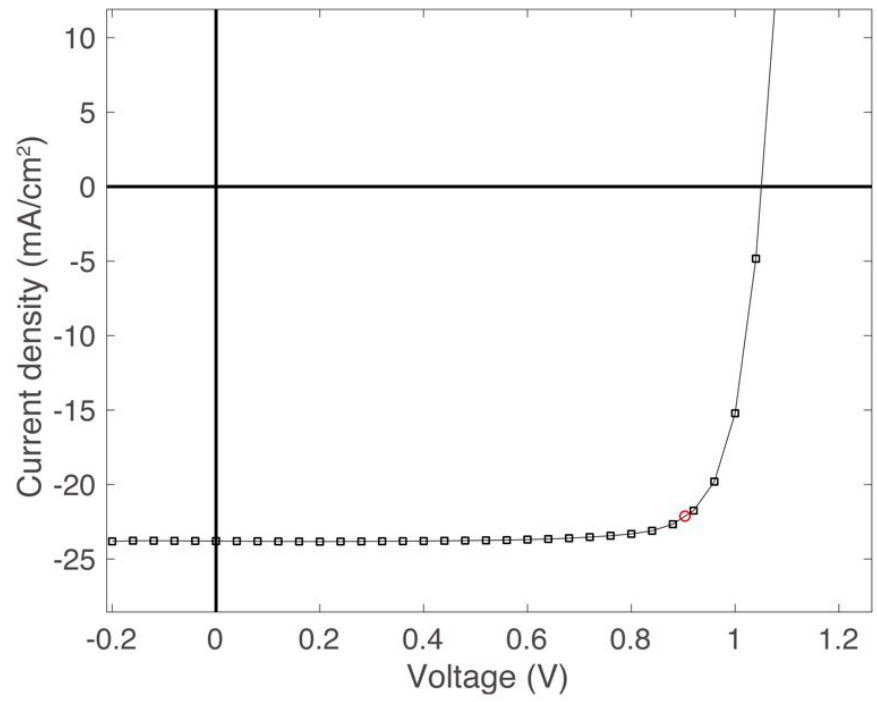

Fig. S25 Current density-voltage curve of a FA(CsMA) $\mathrm{PbI}(\mathrm{Br})_{3}$ device prepared under white light. 
References

(1) Zhao, Z.; Cao, H.; Li, J.; Zhu, H.; Yang, L.; Yin, S. Strategies to Obtain Stoichiometric Perovskite by Sequential Vapor Deposition Learned by Modeling the Diffusion-Dominated Formation of Perovskite Films. Appl. Phys. Express 2018, 11 (10), 105501.

(2) Chen, X.; Cao, H.; Yu, H.; Zhu, H.; Zhou, H.; Yang, L.; Yin, S. Large-Area, High-Quality Organic-Inorganic Hybrid Perovskite Thin Films via a Controlled Vapor-Solid Reaction. J. Mater. Chem. A 2016, 4 (23), 9124-9132.

(3) Kohn, W.; Sham, L. J. Self-Consistent Equations Including Exchange and Correlation Effects. Phys. Rev. 1965, $140(4), 1133-1138$.

(4) Kresse, G.; Joubert, D. From Ultrasoft Pseudopotentials to the Projector Augmented-Wave Method. Phys. Rev. B 1999, 59 (3), 1758-1775.

(5) Kresse, G.; Furthmüller, J. Efficient Iterative Schemes for Ab Initio Total-Energy Calculations Using a Plane-Wave Basis Set. Phys. Rev. B - Condens. Matter Mater. Phys. 1996, 54 (16), 11169-11186.

(6) Perdew, J. P.; Burke, K.; Ernzerhof, M. Generalized Gradient Approximation Made Simple. Phys. Rev. Lett. $1996,77(18), 3865-3868$.

(7) Heyd, J.; Scuseria, G. E.; Ernzerhof, M. Hybrid functionals based on a screened Coulomb potential, J. Chem. Phys. 2003, 118 (18), 8207-8215.

(8) Meggiolaro, D.; De Angelis, F.; First-Principles Modeling of Defects in Lead Halide Perovskites: Best 
Practices and Open Issues, ACS Energy Lett. 2018, 3, 2206 .

(9) Menéndez-Proupin, E.; Palacios, P.; Wahnón, P.; Conesa, J. C. Self-consistent relativistic band structure of the CH3NH3PbI3 perovskite, Phys. Rev. B 2014, 90, 045207 .

$$
\text { Feng, H.-J.; Paudel, T. R.; Tsymbal, E. Y.; }
$$

Zeng, X. C. Tunable Optical Properties and Charge

Separation in $\mathrm{CH} 3 \mathrm{NH}_{3} \mathrm{Sn}_{\mathrm{x}} \mathrm{Pb}_{1-\mathrm{x}} \mathrm{I}_{3} / \mathrm{TiO}_{2}$-Based Planar

Perovskites Cells. J. Am. Chem. Soc. 2015, 137 (25),

$8227-8236$.

(11) Yin, W. J.; Shi, T.; Yan, Y. Unusual Defect Physics in CH3NH3PbI3

Perovskite Solar Cell Absorber. Appl. Phys. Lett. 2014, 104 (6), 063903.

(12) Buin, A.; Comin, R.; Xu, J.; Ip, A. H.; Sargent, E. H. Halide-Dependent Electronic Structure of Organolead Perovskite Materials. Chem. Mater. 2015, 27 (12), 44054412 .

(13) Meggiolaro, D.; Mosconi, E.; De Angelis, F. Formation of Surface Defects Dominates Ion Migration in Lead-Halide Perovskites. ACS Energy Lett. 2019, 4 (3), 779-785. 